\title{
Role of Clinical Examination in the Diagnosis of Breast Cancer
}

Hassan Moaiery, ${ }^{1}$, Mojgan Nabatzadeh², Mohammad Esmaeil Akbari ${ }^{3}$, Bushra Zareie ${ }^{4}$, Mohammad Aziz Rasouli $^{5}$

1. Assistant professor, Department of Surgery, Kurdistan University of Medical Sciences, Sanandaj, Iran ORCID ID: 0000-0003-3221-476X. Tel: +989126505221. E-mail: moaiery@ gmail.com

2. MD. Cancer Research Center, Shahid Beheshti University of Medical Sciences, Tehran

3. Professor, Cancer Research Center, Shahid Beheshti University of Medical Sciences, Tehran, Iran ORCID ID: 0000-0002-5742-426X

4. PhD Student of Epidemiology, Department of Epidemiology, School of Public Health, Hamadan University of Medical Science, Hamadan, Iran ORCID ID: 0000-0002-8307-4835

5. M.Sc. of Epidemiology, Clinical Research Development Unit, Kowsar Hospital, Kurdistan University of Medical Sciences, Sanandaj, Iran ORCID ID: 0000-0003-3359-774X

\section{ABSTRACT}

Background and Aim: Breast cancer is the most common malignancy among women in the world. Timely use of appropriate diagnostic methods in the early stages of this cancer can reduce its consequences and mortality.

Materials and Methods: 287 women with breast mass referring to the Breast Cancer Research Center affiliated to Shahid Beheshti University of Medical Sciences, Tehran (Iran) participated in this cross-sectional study. Demographic data, clinical manifestations and drug history were recorded. Clinical examinations were carried out by a qualified physician. Finally, the correspondence between the data obtained from the clinical examinations with the pathologic results was evaluated.

Results: 287 women with breast cancer (age range: 22-84 year old) participated in the study. Mean and standard deviation (SD) of participants' age was $47.71 \pm 11.62$. Based on pathology results 64 subjects $(22.30 \%)$ had benign and $223(77.70 \%)$ had malignant lesions. 37 subjects $(12.89 \%)$ had benign and $250(87.11 \%)$ had malignant lesions on the basis of the clinical breast examination (CBE). Sensitivity and specificity of CBE were $98.21 \%$ and $51.56 \%$, and also, positive predictive value (PPV) and negative predictive value (NPV) were $87.6 \%$ and $89.19 \%$ respectively. Younger women were less likely to have malignant breast mass compared to older women. Moreover, a significant difference was found between unemployed and employed women as well as between menopausal and non-menopausal women.

Conclusion: The results of the present study showed that clinical examination by skilled physicians can still be an important, highly sensitive and reliable method for diagnosis of breast cancer, especially in the patients who had breastfed their infants for more than 24 to 72 months, and menopausal women or patients with more than 3 pregnancies.

Keywords: Breast cancer, Clinical breast examination, Sensitivity, Specificity Received: Dec 28, 2019 Accepted: Oct 4, 2021

How to cite the article: Hassan Moaiery', Mojgan Nabatzadeh, Mohammad Esmaeil Akbari, Bushra Zareie, Mohammad Aziz Rasouli. The Role of Clinical Examination in the Diagnosis of Breast Cancer Patients.वُQ́SJKU 2021;26(6):1-10.

Copyright (C) 2018 the Author (s). Published by Kurdistan University of Medical Sciences. This is an open access article distributed under the terms of the Creative Commons Attribution-Non Commercial License 4.0 (CCBYNC), where it is permissible to download, share, remix, transform, and buildup the work provided it is properly cited. The work cannot be used commercially without permission from the journal 


\section{نقش معاينه بالينى در تشخيص بيمار ان مبتلا به سرطان خِّتان}

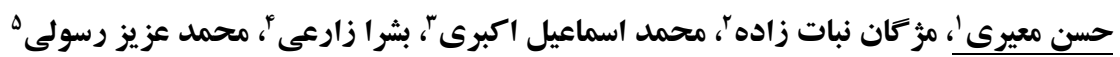

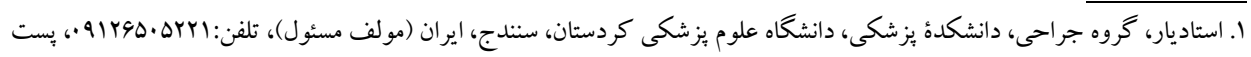

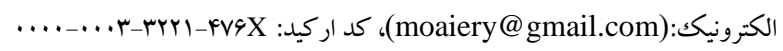
ז. دكترى حرفه اى، مر كز تحقيقات سرطان، دانشكاه علوم يز شكى شهيد بهشتى، تهران، ايران. كد اركيد: r. استاد، مركز تحقيقات سرطان، دانشكاه علوم يز شكى شهيد بهشتى، تهران، ايران. كد اركيد:

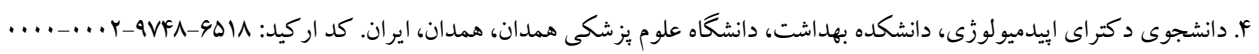

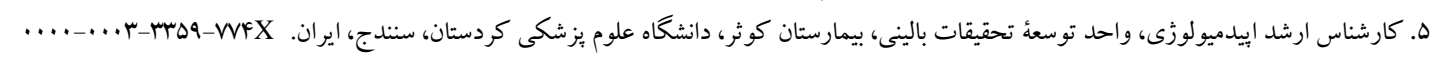

زمينه و هدف: سرطان يستان شايعترين بدخيمى بين زنان در جهان است و با استفاده از روشهاى تشخيصى مناسب و به موقع در مراحل اوليه سرطان مىتوان عواقب بيمارى و مر گكومير آن را كاهش داد. روش بروسى: در اين مطالعه مقطعى YAV نفر از زنان مراجعه كننده به مركز تحقيقات سرطان يُتان وابسته به دانشگاه علوم بزشكى شهيد بهشتى تهر ان (اير ان) با شكايت توده يستان تحت بررسىهاى لازم شامل اطلاعات دمو گر افيك، تظاهرات بالينى و سو ابق دارويى ليى و معاينه بالينى توسط يزشك ماهر انجام شدو در نهايت اطلاعات استخراج شده از معاينه بالينى با نتايج ياتولوزى مطابقت داده شد.

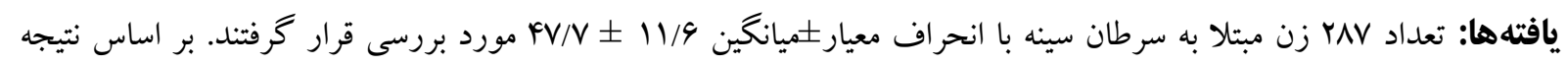

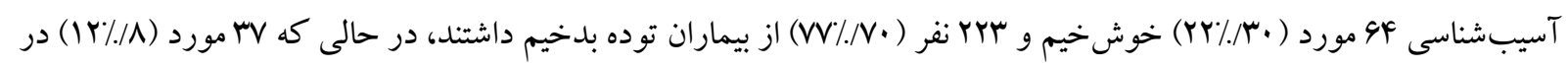

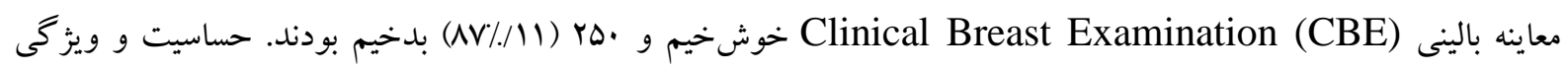
CBE

نتيجه Fيرى: نتايج مطالعه حاضر نشان داد كه هنوز معاينه بالينى توسط افر اد يزشك ماهر با حساسيت بالا مى تواند روش مهم و قابل

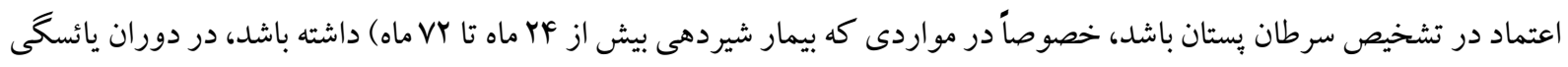
باشد و يا تعداد حاملكى بيش از م تا داشته باشد. وازه هاى كليدى: سرطان بستان، معاينه بالينى يستان، حساسيت، ويزّ

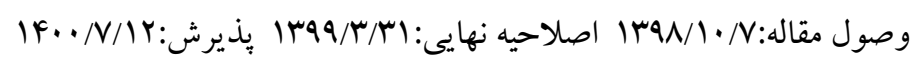


مطالعات إيدميولوزيكك از حساسيت CBE نشان داده كه در ارتباط با سايز تومور سن زنان در زمان تشخيص دارد ولى با بالي نزاد، فاكتورهاى بارورى، نمايه توده بدنى ارتباطى مشاهده

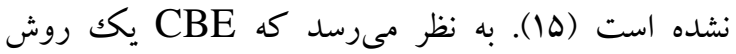
اميدواركننده در بيشخيرى از مركُومير از سرطان بـتهان باشد. اين بتانسيل بستخى به مهارت افرادى دارد كه معاينه

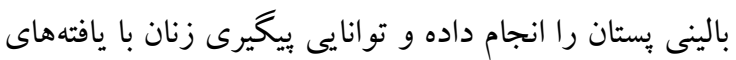
مثبت را در جهت ارائه درمان مناسب در سيستم مراقبت يز شكى دارند(IV) (IV). نكته اساسى ديخر در انتخاب روشهاى دارندان تشخيصى مناسب مقرون به صرفه بودن و در دسترس بودن اين موداليته هاى تشخيصى است كه نياز به توجه خاص دارد كه مى تواند در كشورهاى توسعه يافته و در حال توسعه با هم متفاوت باشد. معاينه بالينى به عنوان اولين و ارزانترين روش تشخيصى در سرطان بستان شناخته مىشود و خصوصاً در شرايطى كه امكان غربالكرى وجود ندارد از اهميت بالاترى برخوردار

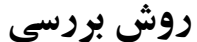

در اين مطالعه مقطعى بهصورت سرشمارى تعداد YAV نفر از زنان مر اجعه كننده با شكايت توده بستان به كلينيك تخصصى دهى

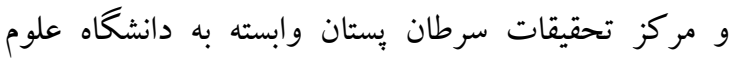
يزشكى شهيد بهشتى تهران (ايران) در بازه زمانى مردادماه

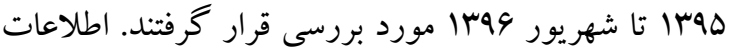
بيماران شامل اطلاعات دمو گر افيك، تظاهر ات بالينى و سوابق دارويى از طريق بررسى برونده بيماران و معاينه بالينى افراد

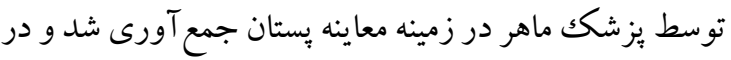
نهايت اطلاعات استخراج شده از معاينه بالينى با نتايج

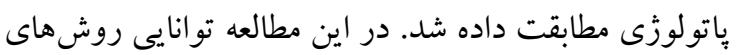
تشخيصى براى افتراق تودههاى بدخيم از خوشخيم از جمله

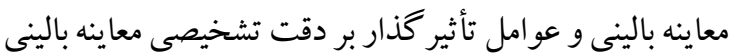

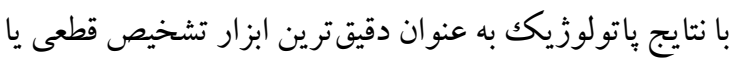
استاندارد طلايى (Gold Standard) تشخيصى مقايسه شد.
سرطان پِتان شايعترين بدخيمى بين زنان است(1)، بهورى كه بر اساس نتايج

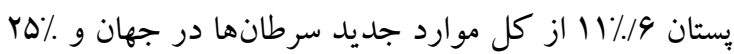
سرطانها در بين زنان را تشكيل مىدهد. اين سرطان جالش بزر گكترى در كشورهاى در حال توسعه است.(r, r). تفاوت ميزان مر كى به علت اين بيمارى در نقاط مختلف دنيا

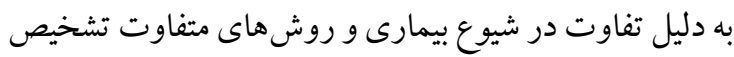
و درمان بيمارى است( أوها). تشخيص زودرس اين سرطان مى تواند در درمان موفقيت آميز

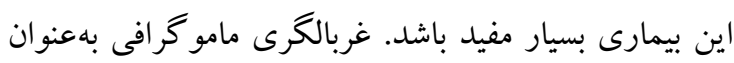
بهترين روش بيماريابى در بسيارى از كشورهاى جهان به كار

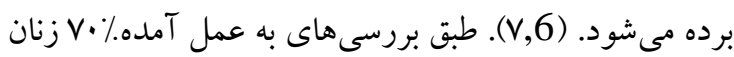

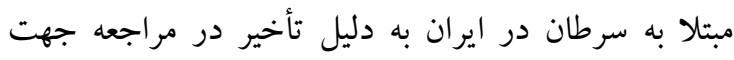

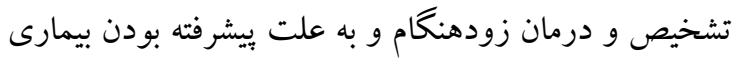
در مدت كوتاهى فوت مى كنند كه مى تواند ناشى از عدم آكاهى و عدم دسترسى به موداليته هاى تشخيصى و درمانى در كشور باشد(1). حدود. ^م سرطان هاى بستان در زنانى

ديده مى شود كه هيج عامل خطرى نداشته اند (9).

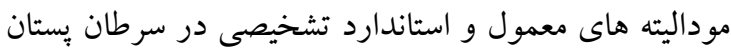

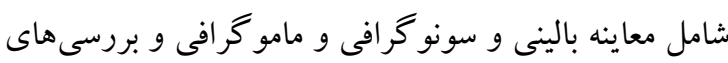

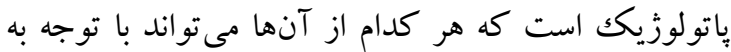
اينكه وابسته به فرد است در شرايط مختلف نتايج متفاوتى را

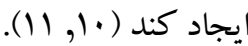

هر كدام از اين موداليته ها از حساسيت متفاوتى در تشخيص اوليه سرطان بِستان برخوردار است و هر كدام نقاط ضعف و قوت مخصوص به خود را دارد البته مهارت در انجام معاينه بالينى و تفسير مامو گرافى و گزارش سونو گرافى توسط افراد مختلف كه از مهارت هاى مختلف برخودار هستند، مى تواند بسيار در تشخيص افتراقى تودههاى خوشخيم از بدخيم مؤثر باشد(rا, برا). در كشورهاى درحال توسعه، روش CBE بيشتر در غربالكرى سرطان بِتان استفاده مى شود(19-1f). 
آزمون آمارى كاى دو و تست دقيق فيشر مشخص شد و براى آن دسته از متغيرهايى كه در اين مرحله P>0.2 بود، با استفاده از آناليز رگرسيون لجستيك جند متغيره، نسبت شانس تطبيق يافته جهت برآورد مدل نهايى ارائه شد. تحليل ها با استفاده از نرم افزار 14.0 Stata/SE انجام كرفت. سطح معنى دارى در اين مطالعه P>0.05 در نظر كرفته شد.

\section{يافته ها}

تعداد YAV زن مبتلا به سرطان سينه بF-YY سال و انحراف

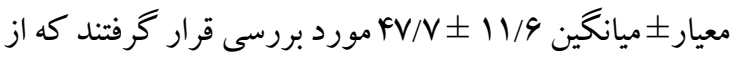

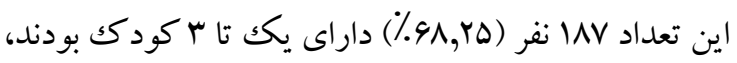

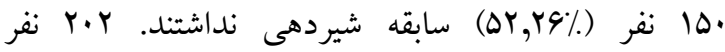
(V.\%/NA)

$$
\text { بودند (جدول ()). }
$$

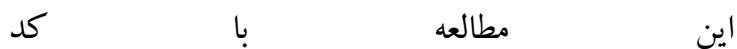

اخلاق IR.SBMU.RETECH.REC.1397.423 ثبت كرديده است.

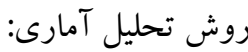
به منظور ارزيابى روش معاينه بالينى (به عنوان يك تست تشخيصى) با نتايج ياتولوزى(Gold Standard) در تمايز ضايعات خوش خيم از بدخيم، شاخصهاى آمارى همجِون، حساسيت، ويز گى، ارزش اخبارى مثبت (PPV)، ارزش اخبارى منفى (NPV)، (Kappa)، محاسبه و سطح زير منحنى راك (Roc Area) گزارش گرديد. هر يكك از شاخص هاى مذكور به تفكيك سن زمان تشخيص، تعداد حاملكى، مدت زمان شيردهى، يائسگى، هورمون درمانى، سن منار كك و سابقه خانو اد گى محاسبه شد. در نهايت با در نظر گرفتن نتايج ياتولوزى به عنوان متغير باسخ، ارتباط بين توده سرطانى بدخيم با ساير متغيرهاى مستقل با استفاده از

جدول ا. توزيع متغير هاى دمو كرافيك در زنان مبتلا به سرطان يستان

\begin{tabular}{|c|c|c|c|}
\hline بدخيم & خوش خيم (\%) تعداد & كل) & متغير \\
\hline$M(Y \wedge / 1)$ & Fq $(V / / 9)$ & $I V \cdot(\Delta Q / Y)$ & سن زمان تشخيص •ه سال> \\
\hline $99(F F / F)$ & $\operatorname{ITF}(\Delta \Delta / 9)$ & $\operatorname{lIV}(\boldsymbol{F} \cdot / \Lambda)$ & . \\
\hline$F \wedge / \wedge(11 / 9)$ & $F \wedge / \wedge(q / F)$ & $F V / V(11 / 9)$ & سن (زمان تشخيص)(انحر اف معيار土ميانگين) \\
\hline $\operatorname{lr}(V V / F)$ & MG (YY/G) & $1 \Delta 9(\Delta \Delta / f)$ & سن منار كs \\
\hline $1 \cdots(V \wedge / 1)$ & $Y \wedge(Y \backslash / Q)$ & $\operatorname{ITA}(F F / 9)$ & $<1 r$ \\
\hline $\mid r / F(I / V)$ & $|r /|(1 / \Delta)$ & $\mid r / F(I / V)$ & سن منار كك (انحر اف معيار土 ميانخين) \\
\hline$I V T(V \Delta / r)$ & $\Delta V(Y F / \Lambda)$ & $r \mu \cdot(\Lambda \cdot / 1)$ & شاغل بودن خير \\
\hline$\Delta \cdot(\wedge \mathrm{V} / \mathrm{V})$ & $V(I r / Y)$ & $\Delta V(19 / V)$ & بله \\
\hline rq (A.) & $q(Y \cdot)$ & $f \Delta(19 / 4)$ & تعداد حاملكى صفر \\
\hline $\operatorname{IFr}(V \Delta / 9)$ & $F \Delta(Y F / I)$ & $\operatorname{INV}(\mathcal{G} / Y)$ & $r-1$ \\
\hline$r \Delta(\Lambda \mu / \Gamma)$ & $V(19 / V)$ & $\operatorname{Fr}(\mid \Delta / \Gamma)$ & $>r$ \\
\hline $119(\mathrm{VV} / \mathrm{r})$ & $M F(Y Y / V)$ & $10 \cdot(\Delta r / \Gamma)$ & مدت زمان شيردهى هر گز \\
\hline$f \cdot(V q / 9)$ & $\mathbb{I r}(Y M / I)$ & $\Delta r(\mid N / 1)$ & oاه \\
\hline$f \cdot(V \wedge / f)$ & $\|(Y \backslash / \Lambda)$ & $\Delta I(I V / \Lambda)$ & 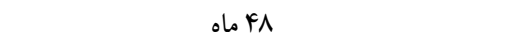 \\
\hline$r F(V Q / F)$ & $V(r \cdot 19)$ & $\mu F(11 / \Lambda)$ & ماه \\
\hline rIr (WV/9) & GY $(Y Y / \Delta)$ & TVD $(9 \Delta / \wedge)$ & محل سكونت \\
\hline $1 \cdot(\Lambda \Gamma / \Gamma)$ & $r(19 / V)$ & $\mathbb{M}(F / Y)$ & 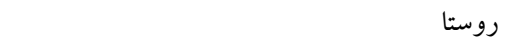 \\
\hline
\end{tabular}




\begin{tabular}{|c|c|c|c|c|}
\hline$r \backslash \Lambda(V / r)$ & $G F(Y Y / V)$ & rAY $(Q \Lambda / \Gamma)$ & خير & مصرف سيگار \\
\hline$\Delta(1 \ldots)$ & $\cdot(\cdot)$ & $\Delta(I / V)$ & & بلd \\
\hline$r \cdot(V / / F)$ & $\wedge(Y \wedge / \mathcal{G})$ & rA $(\mathbf{Q} / \mathrm{V})$ & درجه 1 & سابقه خانوادگى \\
\hline$r \Delta(V \Delta / V)$ & $\Lambda(Y F / Y)$ & (1/D) (TH & & ב درجه r \\
\hline IVA (VA/V) & $F \wedge(Y \backslash / Y)$ & rrV (VA/V) & & خير \\
\hline $\mid F \wedge(V / T / \Gamma)$ & $\Delta F(Y G / V)$ & $r \cdot r(V \cdot / F)$ & خير & يائسخى \\
\hline$V \Delta(M \Lambda / Y)$ & $1 \cdot(11 / \mathrm{V})$ & $\Lambda \Delta(Y Q / q)$ & & بله \\
\hline IVI (VG/V) & $\Delta Y(Y r / r)$ & rrr (VV/V) & خير & هو رمون درمانى \\
\hline$\Delta r(\Lambda \backslash / Y)$ & $\operatorname{Ir}(\mathrm{I} / \mathrm{V})$ & $G F(Y Y / Y)$ & & بله \\
\hline
\end{tabular}

بدخيم بودند. حساسيت و ويزگى CBE برابر با آ//\%ه و و

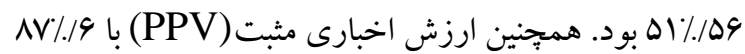

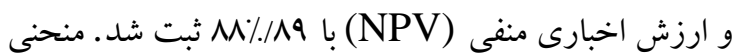
راكك (ROC) در نمودار ا نشان داده شده است.

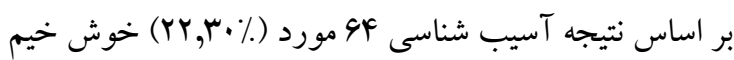

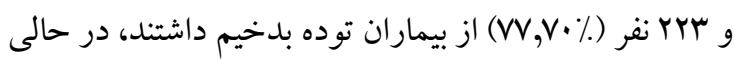

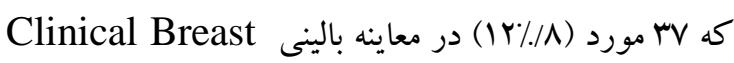
(Av//III) ro. خوشخيم و Examination (CBE)

نمودار ا. منحنى راكى (ROC) معاينه بالينى در تشخيص سرطان يستان

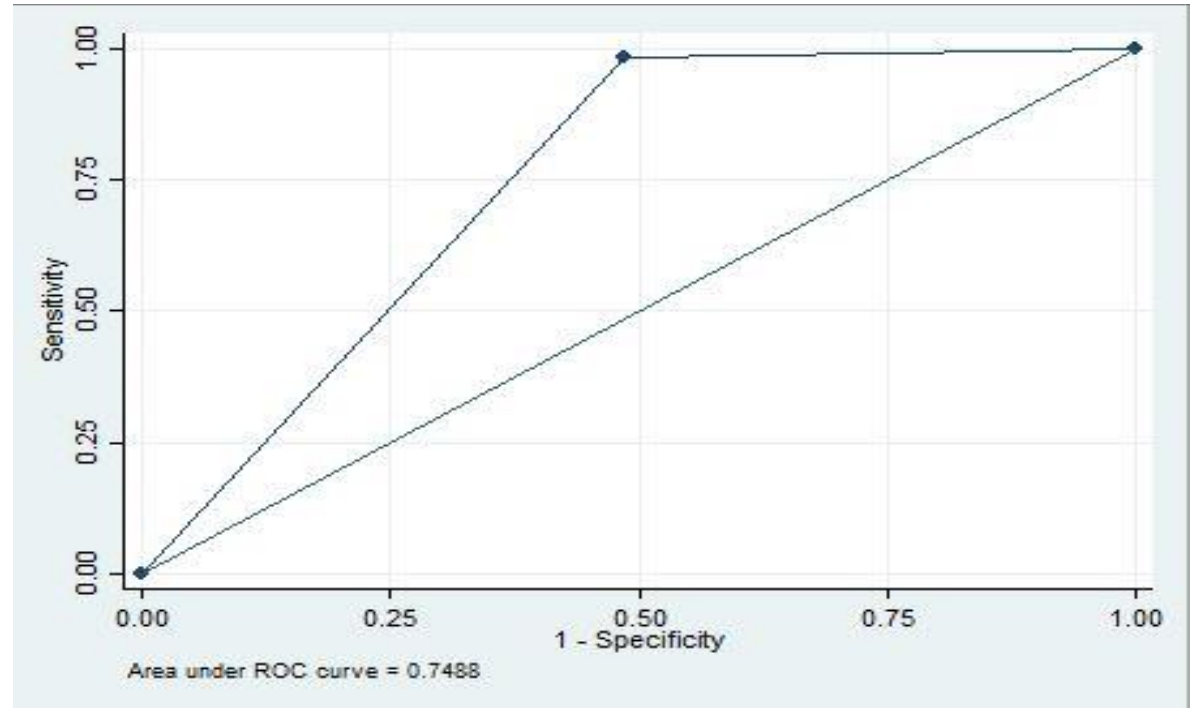

سن مناركى داشته باشند (حساسيت؛ 94\%/VD در مقابل

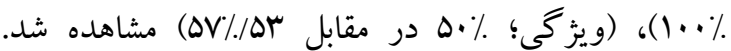
هنگامى كه فرد ا تا ب حاملكى داشته باشد، حساسيت و ويثز گیى افزايش مىيابد (حساسيت؛

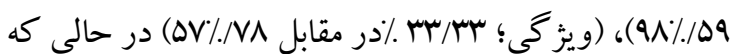

حساسيت و ويزگ گیى براى خانمهايى كه هيج گونه سابقه شيردهى نداشتند به ترتيب برابر ه/ه و ه/ •ه درصد بود، در حالى كه تعداد ماههاى تغذيه باعث افزايش حساسيت معاينه

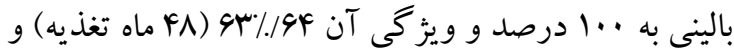

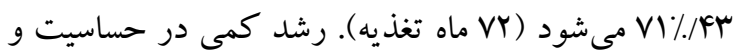
اختصاصى بودن معاينه بالينى براى زنانى كه بيش از سا سال 
با ب حاملكى و بيشتر حساسيت به . .. ا٪ افزايش يافته؛ ولى

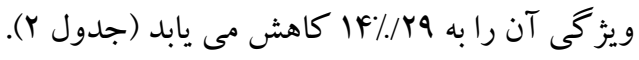

جدول r. ميزان حساسيت، ويزگىى، ارزش اخبارى مثبت، ارزش اخبارى منفى، منحنى راكى و مقدار كاٍا محاسبه شده در زنان مبتلا به سرطان سينه

\begin{tabular}{|c|c|c|c|c|c|c|}
\hline ارزش اخبارى منفى & ارزش اخبارى مثبت & كايا & ROC $(95 \% \mathrm{CI})$ & ويز & حساسيت & 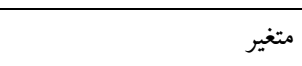 \\
\hline $19 / 94$ & $\wedge \Delta / \wedge r$ & $91 / Y r$ & $\cdot / W V(\cdot / \cdot-V \cdot / \Lambda F)$ & $\Delta G / \Delta r$ & $Q V / \Delta \Lambda$ & سن زمان تشخيص > •ه سال \\
\hline$\wedge V / \Delta$ & $\wedge 9 / 91$ & $\mathrm{Fq} / \cdot \mathrm{r}$ & $\cdot / 99(\cdot / \cdot-\Delta V / A I)$ & M & $91 / 9$ & ב هال \\
\hline$V \Delta / \Delta r$ & $\Lambda \Delta / r V$ & MN/G. & $\cdot / 90(\cdot / \cdot-r q / \Lambda r)$ & 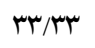 & QV/TY & تعداد حاملكى صفر \\
\hline QY/AG & $\Lambda \Lambda / \cdot \Delta$ & GF/VY & $\cdot /$ VA $(\cdot / \cdot-V \backslash / \Lambda 9)$ & $\Delta V / V \wedge$ & $Q \wedge / \Delta Q$ & $r-1$ \\
\hline $1 \ldots$ & $\Lambda \Delta / \Gamma V$ & YI/VF & $\cdot / \Delta V(\cdot / \cdot-F r / V I)$ & $\mid F / r q$ & $1 \ldots$ & $>r$ \\
\hline$\Lambda \cdot / 9$ & AG/Ar & Dr/Ar & $\cdot / N r(\cdot / \cdot-90 / A r)$ & $\Delta \cdot$ & $99 / \Delta \Delta$ & مدت زمان شيردهى هرگز \\
\hline $1 \cdots$ & 1 & $\mathrm{Fr} / \mathrm{FA}$ & $\cdot / 9 V V \Delta(\cdot / \cdot-\Delta r / \Lambda I)$ & 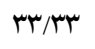 & $1 \ldots$ & ( \\
\hline $1 \ldots$ & $9 \cdot / 9$. & $V \mu / \mu$. & $\cdot / A Y V \Delta(\cdot / \cdot-9 V / 9 V)$ & $9 \pi / 94$ & $1 \ldots$ & Fi fl \\
\hline $1 \ldots$ & $94 / 1$. & $\mathrm{Va} / \mathrm{M}$ & $\cdot / 199(\cdot / 1 \cdots-91)$ & $V I / 4 r$ & $1 \ldots$ & ماه VY \\
\hline$\wedge \mathrm{V} / \Delta$ & $\Lambda F / V I$ & $\Delta \varphi / 4 \Delta$ & $\cdot / N \Delta(\cdot / \cdot-9 N / \Lambda 1)$ & $\Delta 1 / \wedge \Delta$ & $9 V / r$. & يائسگَى \\
\hline $1 .$. & $a r / v \Delta$ & Gr/Ar & $\cdot / V \Delta(\cdot / \cdot-\Delta q / 91)$ & $\Delta \cdot$ & $1 \ldots$ & بله \\
\hline$\Lambda V / \Delta$ & $V \wedge / F r$ & $\Delta q / F V$ & $\cdot / V 9(\cdot / \cdot-99 / \wedge r)$ & $\Delta r / \Lambda \Delta$ & $9 V / 94$ & هورمون درمانى خير \\
\hline $1 \ldots$ & $\Lambda \Lambda / I F$ & $\Delta r / V r$ & $\cdot / N /(\cdot / \cdot-\Delta 9 / \wedge \Delta)$ & $F \mid / 9 V$ & $1 \ldots$ & بله \\
\hline Al/Ar & $19 / 09$ & $\Delta F / Y$. & $\cdot / N r(\cdot / \cdot-90 / A r)$ & $\Delta$. & ৭৭/Vब & سن منارك $\quad$ س \\
\hline $1 \cdots$ & $\Lambda \Lambda / \Delta$ & GF/MY & $\cdot / \mathrm{VV}(\cdot / \cdot-9 \mathrm{~V} / 199)$ & $\Delta r / \Delta V$ & $1 \ldots$ & $>1 r$ \\
\hline $1 \ldots$ & س & $\Delta \Lambda / \Lambda r$ & $\cdot / V \Delta(\cdot / \cdot-\Delta q / Q q)$ & $\Delta \cdot$ & $1 \cdots$ & سابقه خانو ادگى درجه 1 \\
\hline VD & Ar/VG & $4 \cdot / 49$ & $\cdot / 9 V(\cdot / \cdot-F N / A \Delta)$ & $\mathrm{rV} / \mathrm{\Delta}$ & 99 & درجه r \\
\hline $19 / 94$ & NA/Ar & $91 / 40$ & $\cdot / \mathrm{V} 9(\cdot / \cdot-99 / \wedge r)$ & $\Delta F / I V$ & Q४/r। & 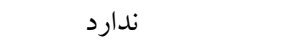 \\
\hline $19 / 19$ & $\Lambda V / 9$. & $\Delta q$ & $\cdot / \mathrm{VD}(\cdot / \cdot-99 / 1 \cdot)$ & $\Delta 1 / \Delta 9$ & $9 \wedge / Y)$ & كل \\
\hline
\end{tabular}

نتايج رگرسيون لجستيك جند متغيره نشان داد كه شانس

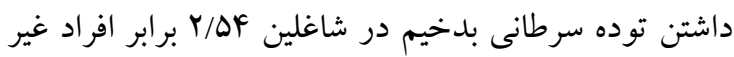

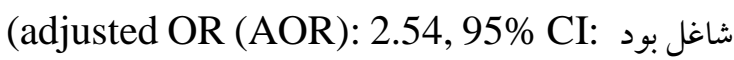
(5.97) 1.08 همجنين شانس توده بدخيم در زنان يائسه

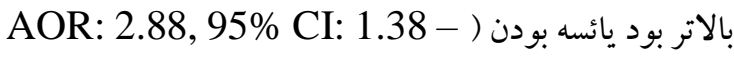

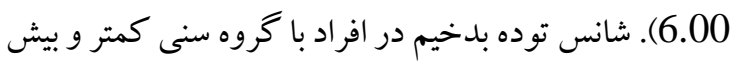
از •ه سال ارتباط معنىدارى را نشان نداد (جدول ؟). 


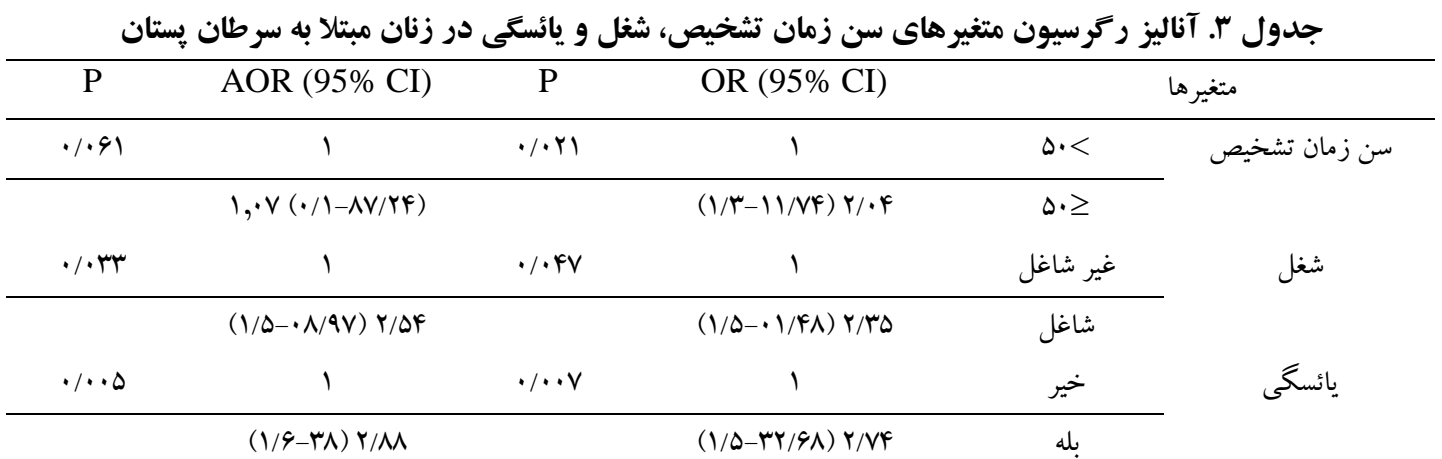

در مطالعهاى در نيجريه، از مقايسه دو روش سونو گرافى و

در تشخيص سرطان يُتان •rr نفر از زنان حامله انجام

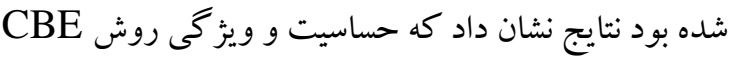
در اين مطالعه به ترتيب .94,V\% و 99\% و در التراسونو گرافى

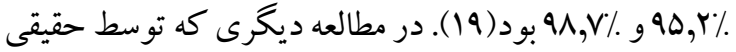
و همكاران در ايران انجام شده بود حساسيت CBE برابر با 99\% كزارش شده بود(·r). همجنين در مطالعات ديخر از مقايسه حساسيت در روش CBE از نظر Effectiveness و Efficacy در مطالعات كار آزمايى بالينى به تنهايى انجام نشده است( (Y). تفاوت حساسيت بالاى روش CBE در اين

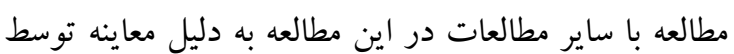
يزشك ماهر و در ساير مطالعات توسط برستار و يا بزشكان باشد كه تشخيص توسط يزشك ماهر و آموزش ديده و در

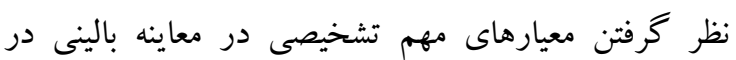
افزايش حساسيت روش و تشخيص سرطان بستان بسيار مهم

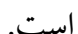
مقايسه نتايج مطالعه حاضر از نظر متدولوزى با ساير مطالعات نيز متفاوت است به طورى كه در اين مطالعه افرادى كه

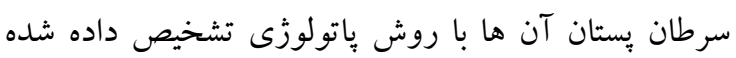

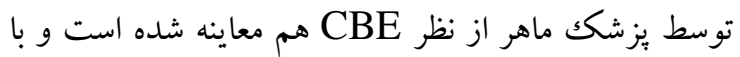
برنامه غربالخرى متفاوت است. همجينين مقايسه حساسيت روش CBE با ساير روش هاى ديخر در تشخيص سرطان

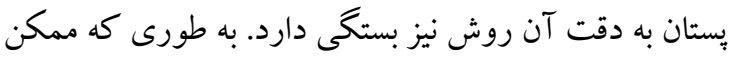

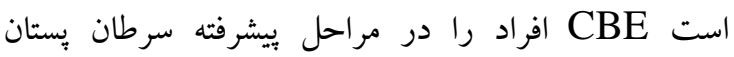

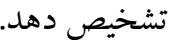
اين مطالعه نشان داد كه حساسيت بالاى تشخيصى معاينه بالينى توسط بز شكك ماهر در افتراق تودههاى بدخيم از خوشخيم و عوامل مؤثر بر دقت تشخيصى اين موداليته و هزينه بسيار كمتر آن مىتواند در مناطق كمتر توسعه يافته و دسترسى بايين

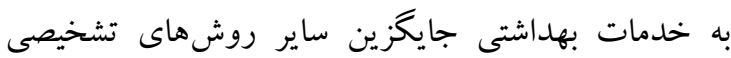

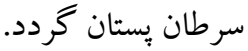
حساسيت و ويز گى اين مطالعه در افتراق تودههاى خوشخيم از بدخيم با معاينه بالينى توسط بزشك ماهر نسبت به ززارش

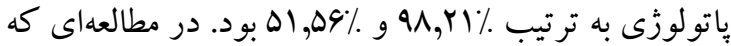

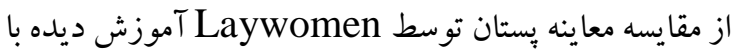
هاير كادر بهداشتى انجام شد حساسيت CBE C C

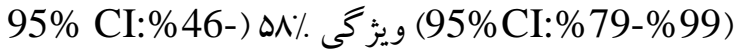

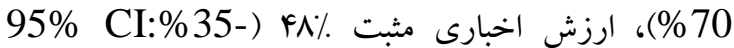
95\% CI:\%85- (4\%2\% و ارزش اخبارى منفى

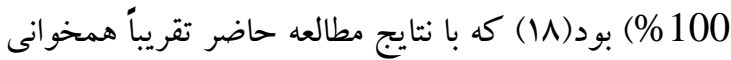

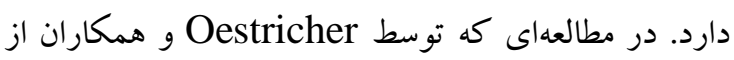
بر رسى \$ \$ نفر مبتلا به سرطان يستان انجام شد نتايج نشان داد كه 190 نفر آنها توسط CBE

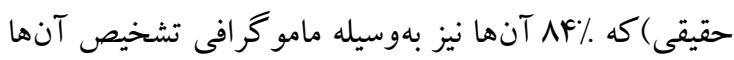
تائيد شده بود و از مواردى كه بهوسيله CBE

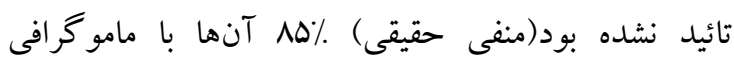

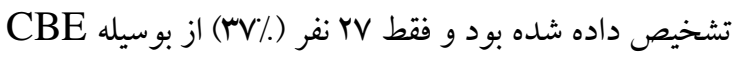
تشخيص آن ها تائيد شده بود(ه)(1). 
در گروه سنى بالاتر بهتر است؛ ولى اكثر گايدلاين ها ييشنهاد

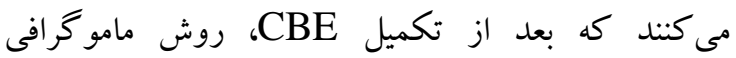
درخواست شود و CBE به تنهايى توصيه نمى گردد (Y9). نتايج ساير مطالعات نيز نشان داد كه حساسيت روش

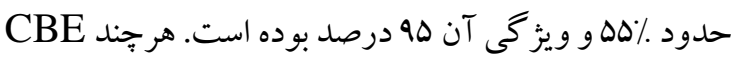

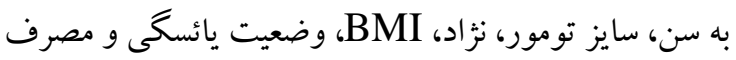

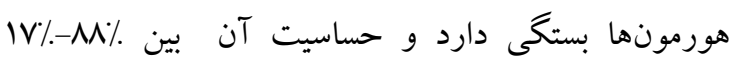

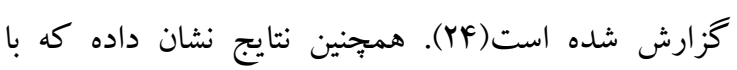
افزايش وزن و BMI در زنان حساسيت CBE كاهش مى دارسي

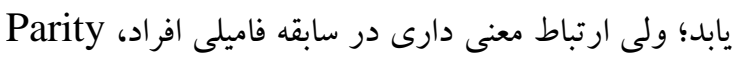

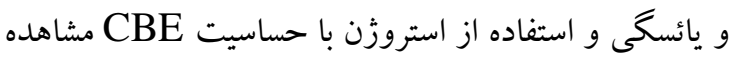

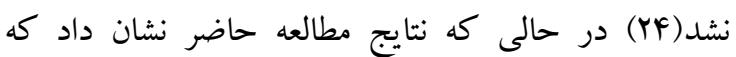

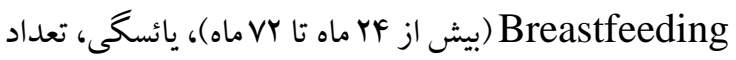
ا CBE بيش از ب و مصرف هورمون حساسيت parity افز ايش مى دهد و ارتباط معنى دارى مشاهده شد.

\section{نتيجه كيرى}

تشخيص زودرس و به موقع اين سرطان تنها راه درمان موفق و حتى در مواردى منجر به درمان قطعى اين بيمارى مىشود.

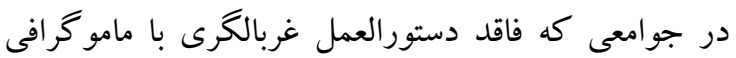

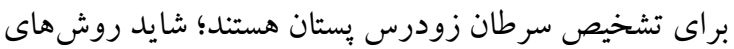
جايكزين بتواند بر تعداد تشخيص هاى زودرس بيفزايد. معاينه بالينى توسط افر اد ماهر يكى از اين راهكارها است كه باوجود حساسيت بالا نمىتوانند در تمامى افراد در مراحل اوليه اين روش را جايخزين روشهاى تصوير بردارى كرد؛ لذا مى توان بيشنهاد داد كه با توجه به نتايج اين تحقيق در افرادى كه نه شيردهى داشته اند (بيش از YF ماه تا VY ماه)، زنان يائسه، زنان با زايمان بيش از Гّ بار و مصرف هورمون هاى استروييدى ندارند اين روش به تنهايى نمى تواند قابليت بالايى در بيمار

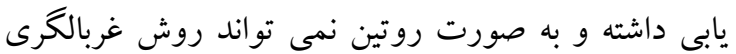
باشد و ضرورتاً از روشهاى تصويربردارى نيز مىبايست در كنار معاينه بالينى بهره جست. هرجند كه بايد گفت در زنانى كه در غربالكرى مامو گرافى (در كشورهايى كه فاقد برنامه
تفاوت زياد حساسيت CBE در اين مطالعه نسبت به ساير مطالعات ديخر اين است كه تشخيص توسط يز شكان ماهر و آشنا به اصول معاينه يُتان و بر اساس معيارهاى استاندارد انجام شده است. در ساير مطالعات به دليل اينكه ممكن است

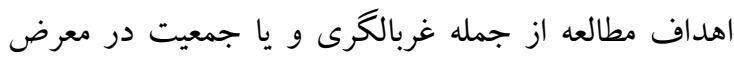
خطر متفاوت باشند مقايسه حساسيت و ويز گیى روش با يكديخر در تشخيص سرطان بِتان سخت است.

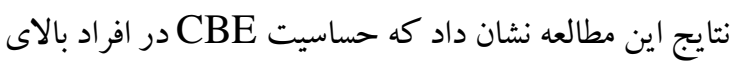

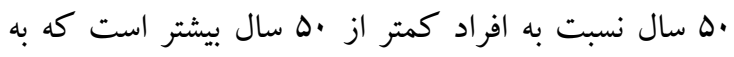

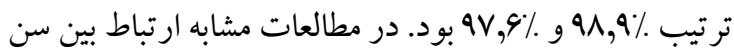
و تشخيص بهوسيله CBE بهصورت U شكل (U shape) بود كه بالاترين حساسيت در زنان با گروه سنى •ه-هوه سال

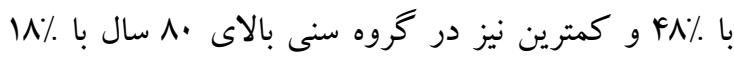

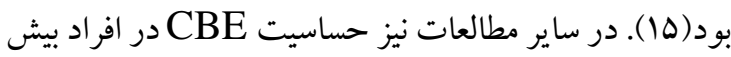

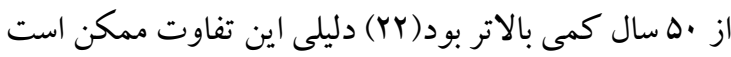
كه تومور در افراد با سن بالاتر بيشرفت بيشترى كرده است.

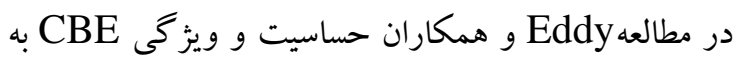
ترتيب \% ه و \$ \$ بود(T)). نتايج يك مطالعه متآآناليز از بررسى مطالعات كار آزمايى بالينى نشان داده كه حساسيت و

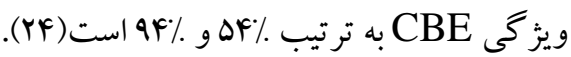
در مطالعه كار آزمايى بالينى از معاينه بالينى بستان در روسيه و جين نشان داد كه نسبت موارد خوشخيم در گروه مداخله و كنترل (بدون مداخله) براى آنها انجام شده بود تفاوتى نداشت. اين مطالعه به دليل اينكه اطمينان كافى از نتايج آن

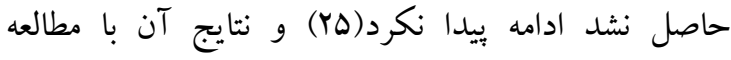

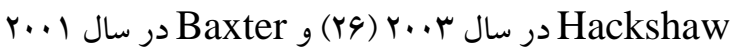

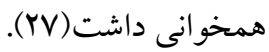
در مطالعهاى از نتايج غربالخرى يستان در كانادا از مقايسه

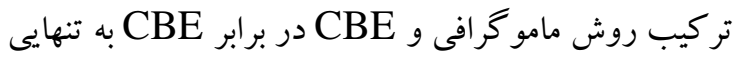
نتايج نشان داد كه تفاوت آمارى معنىدارى در ميزان مرگكومير افراد بعد از با سال بيخيرى مشاهده نشد(YN). هرجند از نتايج آن مطالعه نشان داد كه حساسيت

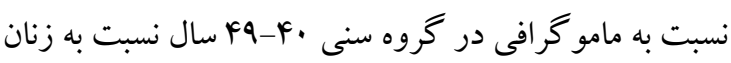




$$
\begin{aligned}
& \text { براى تهيه اين بررسى هيج كمك مالى خاصى از سازمانهاى } \\
& \text { غربالخرى هستند) شركت نمى كنند، معاينه بالينى پستان با }
\end{aligned}
$$

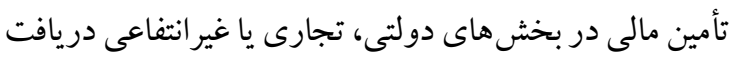

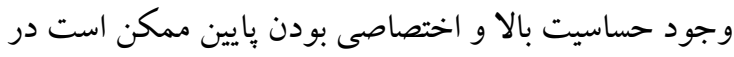

$$
\begin{aligned}
& \text { نشده است. }
\end{aligned}
$$

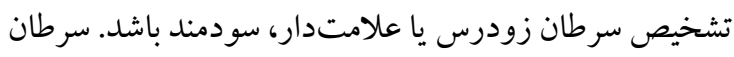

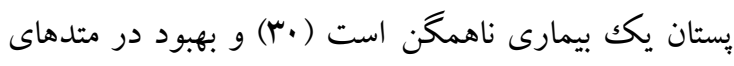

$$
\begin{aligned}
& \text { تشكر و قدردانى }
\end{aligned}
$$

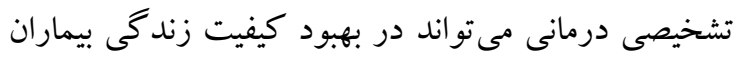

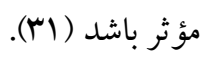

$$
\begin{aligned}
& \text { از كاركنان محترم مركز تحقيقات سرطان دانشـاه علوم } \\
& \text { تضاد منافع } \\
& \text { تشكر مى گردد. }
\end{aligned}
$$

\section{References}

1. Jazayeri SB, Saadat S, Ramezani R, Kaviani A. Incidence of primary breast cancer in Iran: Ten-year national cancer registry data report. Cancer Epidemiol. 2015;39(4):519-27.

2. Bray F, Ferlay J, Soerjomataram I, Siegel RL, Torre LA, Jemal A. Global cancer statistics 2018: GLOBOCAN estimates of incidence and mortality worldwide for 36 cancers in 185 countries. CA: Cancer J Clin. 2018;68(6):394-424.

3. Wahba HA, El-Hadaad HA. Current approaches in treatment of triple-negative breast cancer. Cancer Biol Med. 2015;12(2):106.

4. Wang F, McLafferty S, Escamilla V, Luo L. Late-stage breast cancer diagnosis and health care access in Illinois. Prof Geogr. 2008 Jan 1;60(1):54-69.

5. Lin Y, Wimberly MC. Geographic Variations of Colorectal and Breast Cancer Late-Stage Diagnosis and the Effects of Neighborhood-Level Factors. J Rural Health. 2017;33(2):146-57.

6. Nelson HD, Fu R, Cantor A, Pappas M, Daeges M, Humphrey L. Effectiveness of breast cancer screening: systematic review and meta-analysis to update the 2009 US Preventive Services Task Force Recommendation. Ann Intern Med. 2016;164(4):244-55.

7. Avis NE, Smith KW, Link CL, Goldman MB .Increasing mammography screening among women over age 50 with a videotape intervention. Preventive medicine. 2004;39(3):498-506.

8. Montazeri A, Ebrahimi M, Mehrdad N, Ansari M, Sajadian A. Delayed presentation in breast cancer: a study in Iranian women .BMC women's health. 2003;3(1):4.

9. World Health Organization. Early detection of cancer greatly increases the change of successful treatment. 2005.

10. Evans WP. Breast cancer screening: successes and challenges. CA: Cancer J Clin. 2012;62(1):5-9.

11. Kolb TM, Lichy J, Newhouse JH. Comparison of the performance of screening mammography, physical examination, and breast US and evaluation of factors that influence them: an analysis of 27,825 patient evaluations. Radiology. 2002;225(1):165-75.

12. Hofvind S, Geller B, Skelly J, Vacek P. Sensitivity and specificity of mammographic screening as practised in Vermont and Norway. Br J Radiol. 2012;85(1020):e1226-e32.

13. Kristoffersen Wiberg M, Aspelin P, Perbeck L, Bone B. Value of MR imaging in clinical evaluation of breast lesions. Acta Radiologica. 2002;43(3):275-81.

14. Oeffinger KC, Fontham ET, Wender RC. Clinical Breast Examination and Breast Cancer Screening Guideline-Reply. Jama. 2016;315(13):1404.

15. Oestreicher N, White E, Lehman CD, Mandelson MT, Porter PL, Taplin SH. Predictors of sensitivity of clinical breast examination (CBE). Breast Cancer Res. Treat. 2002;76(1):73-81. 
16. Wagh B, Chaluvarayaswamy R, Pal D. Assessment of Adaptive Breast Cancer Screening Policies for Improved Mortality Reduction in Low to Middle Income Countries. Asian Pac J Cancer Prev (APJCP). 2017;18(9):2375.

17. Weiss NS. Breast cancer mortality in relation to clinical breast examination and breast selfexamination .Breast J. 2003;9:S86-S9.

18. Gutnik L, Lee C, Msosa V, Moses A, Stanley C, Mzumara S, Liomba NG, Gopal S. Clinical breast examination screening by trained laywomen in Malawi integrated with other health services. J Surg Res. 2016 Jul 1; 204(1):61-7.

19. Ezeonu PO, Ajah LO, Onoh RC, Lawani LO, Enemuo VC, Agwu UM. Evaluation of clinical breast examination and breast ultrasonography among pregnant women in Abakaliki, Nigeria. Nco Targets Ther. 2015;8:1025.

20. Haghighi M. Comparative study of clinical breast examination and imaging results to find breast masses. Iran J Radiol. 2005;3(1):22.

21. Albert US, Schulz KD. Clinical breast examination: what can be recommended for its use to detect breast cancer in countries with limited resources? The breast journal. 2003;9:S90-S3. 22. Seidman H, Gelb SK, Silverberg E, LaVerda N, Lubera JA. Survival experience in the breast cancer detection demonstration project. CA: Cancer J Clin. 1987;37(5):258-90.

rr23. Eddy DM. Screening for breast cancer. Ann Intern Med. 1989;111(5):389-99.

24. Bobo JK, Lee NC, Thames SF. Findings from 752081 clinical breast examinations reported to a national screening program from 1995 through 1998. J Natl Cancer Inst. 2000;92(12):9716.

25. Kosters JP, Gotzsche PC. Regular self-examination or clinical examination for early detection of breast cancer. Cochrane Database Syst Rev. 2003;2(2).

26. Hackshaw AK, Paul EA. Breast self-examination and death from breast cancer: a metaanalysis. Br J Cancer. 2003;88(7):1047.

27. Baxter N, Care CTFoPH. Preventive health care, 2001 update: Should women be routinely taught breast self-examination to screen for breast cancer? Can Med Assoc J. 2001;164(13):1837-46.

28. Miller AB, To T, Baines CJ, Wall C. Canadian National Breast Screening Study-2: 13-year results of a randomized trial in women aged 50-59 years. J. Natl. Cancer Inst.. 2000;92(18):1490-9.

29. Smith RA, Saslow D, Sawyer KA, Burke W, Costanza ME, Evans WP, et al. American Cancer Society guidelines for breast cancer screening: update 2003. CA: Cancer J. Clin. 2003;53(3):141-69.

30. Salati A, Akbari ME, Nafissi N, Noorian S, Mahdavi SR, Mirzaei HR, Moayeri H, Shormeij Z, Tutuni M, Saberi N, Shahani M. Comparison of outcome between invasive lobular carcinoma (ILC) and invasive ductal carcinoma (IDC) patients treating with breast conserving surgery (BCS) and radical dose of intraoperative electron radiotherapy (IOERT). Int. J. Cancer Manag. 2018 Nov 30;11(11); e80985

31. Moayeri H, Akbari ME, Nafissi N, Mahdavi SR, Mirzaei HR, Salati A, Khayamzade M, Shormeij Z, Shakeri J, Nabatzadeh M, Shahani M. Outcomes of breast cancer (invasive lobular and ductal carcinoma) treated with boost intraoperative electron radiotherapy versus conventional external beam radiotherapy. Int. J. Cancer Manag. 2019 Jan 31;12(1); e84850. 